\title{
Acceptability of clover flea as prey for common pasture spiders
}

\author{
T. M. Eden ${ }^{1}$, A. Sidhu' ${ }^{2}$ H. Ranson², D.J. Wilson ${ }^{1}$ and P.J. Gerard ${ }^{1}$ \\ ${ }^{1}$ AgResearch, Ruakura Research Centre, Private Bag 3123, Hamilton, New Zealand \\ ${ }^{2}$ WINTEC, Private Bag 3036, Hamilton, New Zealand \\ Corresponding author: tina.eden@agresearch.co.nz
}

Clover flea (Sminthurus viridis) is present throughout New Zealand causing significant damage to white clover (Trifolium repens) in localised areas of the North Island. Insecticides are available for clover flea control, but their use is harmful to beneficial pasture invertebrates. While predatory mites are present in New Zealand pastures, previous research has indicated that they are relatively ineffective at moderating clover flea populations. Other species in pasture, such as spiders, may prove to be more effective predators. The feeding and survival of clover flea was compared when caged with common pasture spiders (Lycosidae or Linyphiidae) at either $15^{\circ} \mathrm{C}$ or $20^{\circ} \mathrm{C}$. Spiders had a significant effect on clover flea survival, and there was no difference between spider families. At $15^{\circ} \mathrm{C}$, clover flea survival in the presence of spiders was less than $21 \%$ compared with $94 \%$ survival in the spider-free controls $(\mathrm{P}<0.001)$. At $20^{\circ} \mathrm{C}$, clover flea survival was further reduced to $12 \%$ compared with $41 \%$ in the controls $(\mathrm{P}<0.001)$. Clover flea feeding scores were significantly lower when caged with spiders $(\mathrm{P}<0.001)$. There were no feeding differences between spider families or temperatures. This work highlights the role beneficial invertebrates can play in controlling pest abundance and damage.

\section{Microctonus hyperodae in Otago and Southland}

\author{
C.M. Ferguson ${ }^{1}$, B.I.P. Barratt ${ }^{1}$, D.M. Barton ${ }^{1}$ and D.J. Wilson ${ }^{2}$ \\ ${ }^{1}$ AgResearch Ltd, Invermay Agricultural Centre, Mosgiel, New Zealand \\ ${ }^{2}$ AgResearch Ltd, Ruakura Research Centre, Hamilton, New Zealand \\ Corresponding author: colin.ferguson@agresearch.co.nz
}

In 1990 Microctonus hyperodae was released in Otago and Southland as a biocontrol agent against Argentine stem weevil (ASW) (Listronotus bonariensis). At that time ASW was New Zealand's major pasture pest but attained only sporadic importance in the southern South Island. Since then, possibly due to higher nutritional qualities of modern ryegrass cultivars and/or changes in annual thermal accumulation, ASW has increased in significance. Farmers once relied on endophyte-free ryegrasses but now sow infected grasses. While endophyte helps protect against ASW damage, augmentation by M. hyperodae parasitism is desirable. Establishment and localised spread of M. hyperodae was measured around the release sites, but subsequent distribution over the wider southern South Island was not. Between September and November 201152 pastures were sampled and ASW was found in all. Microctonus hyperodae was reared from 18 of these pastures at levels of 1-33\% parasitism, but in 15 pastures parasitism was less than $7 \%$. The information gathered covers a limited period but suggests that M. hyperodae is not as successful in the far south as in other parts of New Zealand. The reasons for this and possible implications warrant further investigation both to understand the situation and to investigate if supplementary releases of $M$. hyperodae can be usefully undertaken. 